\title{
Os princípios democráticos fundamentais de segurança e justiça como tópoi retóricos do raciocínio jurídico moderno e a inferência indutiva na criação judicial do direito
}

The fundamental democratic principles of security and justice as modern legal reasoning rhetorical tópoi and the inductive inference in judicial law creation

Pedro Parini Marques de Lima*

\section{Resumo}

Segurança e justiça são tópoi da retórica jurídica. Em abstrato, assumem espectro semântico cuja amplitude leva à indeterminação de seus sentidos. Enquanto tópoi, esses valores são ressaltados como fundamentos éticos para a produção jurídica, mas, a despeito do senso comum teórico, não excluem mutuamente, mesmo em situações concretas relacionadas à decisão judicial. Portanto, não poderiam atuar como premissas ou formulações gerais que levam, dedutiva ou analogicamente, a resultados necessários por meio de uma estrita vinculação entre decisão e norma. Assim, a lógica dos processos decisórios parece indutiva. A cada novo dado, a cadeia indutiva se modifica, alterando seu sentido.

Palavras-chave: Retórica jurídica. Justiça e segurança. Tópoi retóricos. Raciocínio indutivo.

* Professor Adjunto do Departamento de Direito Privado do Centro de Ciências Jurídicas da UFPB; Docente do Programa de Pós-Graduação em Ciêcias Jurídicas da UFPB; Coordenador do grupo de pequisa Retórica, Hermenêutica e Direito. Mestre e Doutor pelo Programa de Pós-Graduação em Direito da UFPE. Pós-doutorado pela Università di Bologna, Itália. João Pessoa - PB - Brasil. Email: pparini@gmail.com 


\section{Abstract}

Security and justice are legal rhetoric's tópoi. Abstractly they develop a semantic spectrum whose broadness leads to indetermination of sense. As tópoi, these values are outlined as ethical foundations of legal production. However, differently from what the theoretical common sense sustains they are not mutually excluded even in the context of actual cases of judicial decision. Therefore, they could not be used as premises or general formulations that lead deductively or analogically to necessary results through a strictly binding between norm and decision. That is why the logic of decisional processes seems to be inductive. With every new data, the inductive chain modifies itself altering its sense.

Keywords: Legal rhetoric. Justice and security. Rhetorical tópoi. Inductive reasoning.

\section{Introdução}

De um ponto de vista axiológico, justiça e segurança são valores que orientam os possíveis rumos da argumentação jurídica e da consequente produção do direito. Tomando em abstrato, são valores que se complementam e caracterizam a própria noção de direito, isto é, conferem sentido ao jurídico e determinam as funções do direito em sua configuração dogmática. Entretanto, o que as tradicionais teorias do direito tomam por certo é que, quando suscitados em concreto, na qualidade de instrumentos pertencentes à tecnologia dogmática de neutralização do dissenso, isto é, diante de um problema concreto ou de um contexto determinado, opõe-se, na medida em que são tomados como valores que se excluem mutuamente e, portanto, não podem ser realizados ao mesmo tempo. O paradoxo surge diante da contraposição entre o ideal e o empírico no direito. Idealmente, para uma definição do jurídico, os valores de segurança e justiça teriam a mesma importância. Empiricamente, por outro lado, a prevalência de um valor impõe geralmente a mitigação do outro. Retoricamente, contudo, tanto o aspecto ideal quanto a sua determinação empírica são relevantes para a consecução dos efeitos persuasivos do recurso a esses valores num 
ambiente linguístico-discursivo. Tudo depende de sua conformação tópica e do raciocínio que se aplica.

Já disse Aristóteles (1996, p. 219 [1391b]) que todo juiz (крıтńs, krités), ou seja, todo aquele que julga ou elabora juízos acerca de algo, é alguém que deve ser persuadido e, dessa forma, todo indivíduo termina por ser um juiz - o que nos leva a subentender que todos nós estamos envolvidos em alguma situação retórica na medida em que carecemos de convencimento ou estamos diante da necessidade de persuasão. Perceba-se que Aristóteles usa o termo krités, e não dikastés (סıкaotńs), de forma que se refere não apenas ao juiz no sentido exclusivamente jurídico (judicial ou forense), mas a todo indivíduo que se coloca como julgador, dando assim proeminência ao processo mental de formulação de juízos em qualquer âmbito e a sua conexão com a persuasão. Claramente, o sentido de "julgar" permanece ambíguo, mesmo depois de mais de dois milênios, mesmo que o "julgamento" no direito assuma conotações específicas. Essa ambiguidade é retoricamente relevante, sobretudo no que se refere ao raciocínio retoricamente determinado, isto é, no juízo tópico.

No texto da Constituição brasileira, as expressões "segurança" e "justiça" aparecem lado a lado, já no preâmbulo, como "valores supremos de uma sociedade fraterna, pluralista e sem preconceitos [...]". Ao longo do texto constitucional, assumem diferentes conotações, com diferentes sentidos técnico-dogmáticos, como no caput do art. $5^{\circ}$, no sentido de "direito à segurança"; ou no inciso XXXIII do mesmo artigo, como "segurança da sociedade e do Estado". No art. 6, segurança aparece como um dos "direitos sociais"; e, no sentido teórico empregado pelos juristas (aqui destacado), fala-se em "grave insegurança jurídica" no $\S 1^{\circ}$ do art. 103-A (incluído no texto da Constituição, no ano de 2004, pela Emenda Constitucional $n^{\circ} 45$, que se refere às súmulas com efeito vinculante, editadas pelo Supremo Tribunal Federal). O valor da justiça é aludido ainda da mesma forma no texto constitucional, por exemplo, no inciso I do art. $3^{\circ}$ como um dos objetivos fundamentais da República Federativa do Brasil, a saber, "construir uma sociedade livre, justa e solidária". 
A dependência em relação ao contexto, bem como a maleabilidade semântica dos dois conceitos nos levam a compreendê-los retoricamente como tópoi do direito, isto é, dos discursos e argumentos formulados pelos juristas. De fato, o caráter tópico das noções de segurança e justiça está relacionado à maneira como os valores são suscitados não só na argumentação, mas também na compreensão do direito. Tradicionalmente, o que se propaga no senso comum dos juristas é que quanto mais segurança se tem, menos possibilidade de se distribuir justiça; e quanto mais justiça, menos segurança se garante. É o que se pode perceber no embate entre as escolas ou movimentos da jurisprudência europeia, entre meados do século XIX e a primeira metade do século $X X$, que se agrupavam sob os rótulos de formalistas e antiformalistas, cuja discussão desembocava no debate acerca da função criadora de direito dos tribunais (KELSEN, 1987, p. 268).

O que se pretende aqui, entretanto, não é aceitar essa tradição argumentativa e hermenêutica da dogmática jurídica, mas questionála criticamente, levando em consideração a possibilidade de inversão semântica dos dois conceitos diante de sua maleabilidade. Isto é, segurança e justiça podem assumir sentidos diferentes e até mesmo intercambiáveis a depender da situação retórica ${ }^{1}$ concreta. Sua suposta oposição não representa de forma alguma problema para o raciocínio do jurista, e sim possibilidade retórica de se desenvolver e manipular topicamente a produção do direito. Faz parte da tradição tomar o problema da oposição desses valores no âmbito das decisões jurídicas, não só judiciais, em sentido estrito - mesmo que em geral o jurídico seja metonimicamente equiparado ao judicial -, mas também de decisões administrativas.

As questões referentes ao problema decisório na esfera jurídica normalmente estão relacionadas às discussões em torno dos limites à criação judicial do direito; na esfera administrativa, dizem respeito à noção de discricionariedade. E é justamente diante desse tema que

Para uma definição do conceito de "situação retórica" cf. Bitzer (1968); Larson (1970); Brinton (1981). 
a oposição entre os princípios jurídicos de segurança e justiça ganha relevância teórica, principalmente no contexto de uma teoria retórica do direito.

Assim, as teses que se pretende desenvolver no âmbito deste texto são as seguintes: em primeiro lugar, segurança e justiça, longe de serem valores que em abstrato atuam na elaboração do direito, funcionam como tópoi da retórica jurídica e mais especialmente da retórica judicial prática no contexto de uma situação retórica determinada. Se fossem tomados idealmente, assumiriam um espectro semântico cuja amplitude levaria a situações de indeterminação de seus sentidos, o que os limitaria em sua funcionalidade operacional. Em segundo lugar, esses tópoi são sempre ressaltados como fundamentos éticos para a produção do direito na modernidade, mas, a despeito do senso comum teórico, não são valores que se excluem mutuamente, mesmo diante de situações concretas relacionadas à decisão judicial. Eles se trasmudam e se adaptam às particularidades de uma situação retórica determinada. Em terceiro lugar, não podem ser tomados como premissas ou formulações gerais que levam, dedutiva ou analogicamente, a resultados necessários por meio de uma estrita vinculação entre decisão e norma legal ou decisão e precedente. Por essa razão, desde um viés retórico, processos inferenciais de tipo indutivo parecem constituir a ferramenta lógica mais adequada à compreensão de processos decisórios, mesmo que tenham uma função meramente representativa.

Se essas teses se confirmam, os conceitos de justiça e segurança serão sempre intercambiáveis, isto é, a noção de segurança poderá ser apresentada como uma forma de justiça, desde que seja entendida como previsibilidade, enquanto a ideia de justiça poderá ser compreendida como segurança, desde que equiparada à igualdade; em segundo lugar, essa maleabilidade semântica tipicamente tópica se deve ao fato de que o raciocínio jurídico é prevalentemente indutivo e as inferências no direito partem dos casos particulares para a formulação de sentidos gerais como os de segurança e justiça, só determinados a posteriori, ou seja, empiricamente diante de um caso. A cada nova inferência, isto é, a cada novo elemento particular que é tomado no procedimento indutivo 
surgem novas conclusões e, consequentemente, novos sentidos para esses tópoi.

\section{Justiça e segurança como tópoi retóricos na criação do direito}

Obviamente, não se pretende elaborar aqui definições omni compreensivas ou mesmo pontuais dos conceitos de segurança e justiça enquanto valores importantes para a orientação do trabalho do jurista. O objetivo deste trabalho é tentar analisar retoricamente como esses tópoi atuam no modo de compreender, produzir e manipular noções e fenômenos - a que se convenciona chamar de jurídicos - que são empregados na construção do que se percebe como sendo a realidade do direito. Ou seja, o que se pretende é elaborar uma análise tópica e retórica ${ }^{2}$ dos conceitos de segurança e justiça e observar a maneira pela qual eles orientam a elaboração do raciocínio jurídico desde o ponto de vista de uma lógica própria da retórica.

De qualquer forma, tanto na filosofia como na teoria do direito, não faltam exemplos de tentativas de definição do que seja justiça, mas também de um sentido especificamente jurídico para o valor da segurança. As teorias jurídicas da finalidade, por exemplo, aquelas que procuram uma definição teleológica de direito, costumam definir o jurídico como a ação que busca o bem comum, isto é, que realiza determinado ideal de bem comum, ou seja, um ideal de justiça, mesmo que não deixem de apresentar apenas fórmulas abstratas de justiça capazes de abrigar qualquer conteúdo (LOSANO, 2007, p. 555). O próprio conceito de bem comum leva a uma cadeia infinita de problemas semânticos e posições ideológicas as mais diversas. A oposição mais abrangente pode ser representada pela dicotomia entre a filosofia do direito dos filósofos e a filosofia do direito dos juristas. Enquanto a primeira costuma partir de axiomas abstratos para chegar a temas

2 Para uma definição do conceito de retórica analítica cf. Ballweg (1982, 1987, 1991a, 1991b). 
especificamente jurídicos, a segunda tende a partir das normas jurídicas positivadas para produzir abstrações (LOSANO, 2003, p. 201). Pode-se representar esses dois percursos intelectuais como um movimento com sentidos opostos que procuram atingir um mesmo ponto de contato, a saber, entre justiça e direito.

É precisamente esse tipo de identificação entre o conceito de direito e o conceito de justiça o alvo das críticas apresentadas pelas teorias jurídicas positivistas. Segundo Hans Kelsen (1998, p. 8), essa identificação equivocada entre os conceitos de justiça e de direito se deve "à tendência ideológica de dar aparência de justiça ao direito positivo", pois "a tendência de identificar direito e justiça é a tendência de justificar uma dada ordem social". Segundo Kelsen, nos limites de seu esquema teorético positivista, trata-se de uma tendência política, e não científica. Mas a questão não é se o direito deve ou não ser justo. Sem dúvida, existe e existirá sempre uma exigência de justiça relacionada à noção de direito. Isso não é negado pelos positivistas que identificam apenas a impossibilidade de determinar cientificamente um conteúdo específico de justiça para o direito ou de responder à questão sobre se uma dada norma é justa ou injusta. Talvez por essa razão Kelsen identifique (provavelmente ironizando) justiça com "felicidade social", pois "o anseio por justiça é o eterno anseio do homem pela felicidade. É a felicidade que o homem não pode encontrar como indivíduo isolado e que, portanto, procura em sociedade" (KELSEN, 1998, p. 9). Mas muito provavelmente a identificação de justiça com felicidade social é uma ironia instrumental formulada por Kelsen. Pois, da mesma forma que não é possível estabelecer uma ordem que proporcione felicidade a todos os indivíduos, tampouco é possível estabelecer um direito que garanta a justiça em termos globais.

Mesmo que se determine que o justo é aquilo que é justo não para todos, mas para grande parte dos indivíduos, no que diz respeito à máxima satisfação de mínimas exigências ou necessidades humanas dignas de serem satisfeitas, uma teoria científica do direito não seria capaz de determinar um sentido próprio de justiça. Para Kelsen (1998, p. 10), as perguntas sobre o que é a justiça e sobre o que diferencia o justo 
do injusto não podem ser respondidas por meio da cognição racional, pois dependem de fatores emocionais e são de caráter subjetivo, isto é, relativas, já que são válidas apenas para o sujeito que julga. E, ainda, mesmo "que muitos indivíduos estejam em concordância quanto aos seus julgamentos de valor não é uma prova de que esses julgamentos sejam corretos" (KELSEN, 1998, p. 12). Nesse sentido, para as teorias positivistas, qualquer conceito ou tentativa de definição de justiça não passam de fórmulas vazias ou tautologias sem sentido. Dessa forma, Kelsen (1998, p. 19) conclui que a justiça é um ideal inacessível à cognição humana, ou seja, uma ideia irracional, por mais indispensável que seja para a volição e ação humanas.

Claro que essa tese só é válida no âmbito de uma ideologia positivista em cujo interior se desenvolve uma teoria do direito. Para correntes teóricas chamadas pós-positivistas, a simples distinção binária entre juízos de realidade e juízos de valor é, em si mesma, questionável. No entanto, mesmo pensadores considerados pioneiros na crítica às teses do positivismo jurídico, como Chaïm Perelman no início de sua carreira, antes de se ater ao projeto de desenvolvimento de uma filosofia prática fundada na retórica e na teoria da argumentação como uma lógica dos juízos de valor, viram-se presos inexoravelmente à oposição entre juízo de realidade e juízo de valor (GIANFORMAGGIO BASTIDA, 1973, p. 21-28). A diferença é que, em sua teoria, no lugar de juízo de realidade, ele fala em juízo de verdade (juízo cuja verdade ou falsidade pode ser comprovada). A tese do jovem Perelman é de que todo conhecimento é, em alguma medida, fundado em juízos de valor, portanto, sempre haverá algum elemento arbitrário na fundamentação de qualquer verificação em geral. A arbitrariedade dos juízos de valor termina, pois, por contaminar, desde a origem, qualquer sistema cognitivo ou explicativo. Os juízos de verdade são necessários, e não contingentes. No entanto, a única espécie de necessidade à qual estaríamos constrangidos a reconhecer seria a necessidade interna de um sistema teórico que se impõe depois que algumas regras arbitrárias são aceitas no início do processo cognitivo de verificação. 
A ideia fundamental é que todo juízo verdadeiro é verdadeiro enquanto expressado em conformidade com uma regra. Essa regra, sendo a medida da verdade, não pode por sua vez ser qualificada verdadeira ou falsa e é, portanto, dita arbitrária. Igualmente arbitrário é qualquer juízo que, acerca de um juízo, afirme a verdade ou a falsidade, de forma que não existe qualquer juízo ou norma por si mesma capaz de se impor universalmente: e isso justifica a tolerância entre grupos portadores de valores contrastantes ${ }^{3}$ (GIANFORMAGGIO BASTIDA, 1973, p. 21-28).

Dessa forma, Perelman (2002), ao tratar do problema da justiça, não tão distante de Kelsen e talvez ainda preso à concepção positivista de ciência e de filosofia, caracteriza a distinção entre pensamento filosófico e científico em razão do grau de emotividade de suas noções fundamentais.

As ciências se separam da filosofia na medida em que, pelo uso dos métodos precisos, experimentais ou analíticos, lograram pôr o relevo em obter o acordo das mentes menos sobre o sentido emotivo das palavras do que sobre o seu sentido conceitual. Quanto mais consistência adquire o sentido conceitual das palavras em todas as mentes, menos se discute sobre o sentido dessas palavras, mais se esfuma sua coloração emotiva (PERELMAN, 2002, p. 15).

Mesmo diante dessas objeções dos positivistas, e, em parte, do que veio a se tornar parte do pensamento pós-positivista, os juristas teóricos não abrem mão de especulações em torno do conceito de justiça. De um primeiro nível de abstração, isto é, das comparações sincrônicas ou diacrônicas dos estudos jurídicos, ou seja, respectivamente, do direito comparado e da história do direito, os juristas passam a um segundo e mais extremo nível de abstração do pensamento jurídico e chegam à

3 "L'idea fondamentale è che ogni giudizio vero è vero in quanto espresso in conformità de una regola. Questa regola, essendo la misura della verità, non può a sua volta esser qualificata vera o falsa, ed è pertanto detta arbitraria. Del pari arbitrario è ogni giudizio che d'un giudizio affermi la verità o falsità cosicché non v'è alcun giudizio o norma di per sé capace d'imporsi universalmente: e ciò giustifica la tolleranza tra gruppi portatori di valori contrastanti". 
filosofia do direito. Esse grau extremo de abstração da realidade deixa quase completamente de lado os dados empíricos das ordens jurídicas que são e um dia foram vigentes para chegar a formulações universais de respostas a problemas gerais do direito em todas as suas possíveis manifestações (LOSANO, 2007, p. 547). Essa abstração, típica dos sistemas filosóficos das filosofias idealistas, procura definir em termos universais um conceito de direito e, claramente, um conceito de justiça que sejam ambos definitivos e até mesmo atemporais.

Nesse sentido, algumas teorias jurídicas procuram definir o direito e suas características de maneira universal, como acontece, por exemplo, com as teorias sistêmicas. É o caso típico da definição sistemática de direito ou da compreensão do direito como um verdadeiro sistema na teoria de Claus-Wilhelm Canaris (1996, p. 18), que afirma o seguinte:

A ordem interior e a unidade do direito são bem mais do que pressupostos da natureza científica da jurisprudência e do que postulados da metodologia; elas pertencem antes às mais fundamentais exigências ético-jurídicas e radicam, por fim, na própria ideia de direito. Assim, a exigência de ordem resulta diretamente do reconhecido postulado da justiça, de tratar o igual de modo igual e o diferente de forma diferente, de acordo com a medida de sua diferença.

Diferentemente de Kelsen, Canaris (1996) não se limita a descrever o direito como um sistema de normas válidas, mas identifica o conceito de sistema e a natureza sistêmica da noção de direito com as exigências éticas de justiça. O caráter sistêmico da ordem jurídica implica a necessária ausência de contradições, o que corresponde à "tendência generalizadora da justiça, que exige a superação dos numerosos aspectos possivelmente relevantes no caso concreto, a favor de uns poucos princípios, abstratos e gerais" (CANARIS, 1996, p. 20). A essa definição do conceito de justiça voltaremos mais adiante na sua análise tópica. Ademais, segundo o autor, uma concepção sistêmica dos fenômenos jurídicos seria responsável por impedir que "a ordem do direito se disperse numa multiplicidade de valores singulares desconexos, antes se deixando reconduzir a critérios gerais relativamente pouco 
numerosos" (CANARIS, 1996, p. 21). Mas, segundo Canaris (1996, p.22), não é apenas o valor da justiça que é garantido pela concepção sistêmica do direito.

Longe de ser uma aberração, como pretendem os críticos do pensamento sistemático, a ideia do sistema jurídico justifica-se a partir de um dos mais elevados valores do direito, nomeadamente do princípio da justiça e das suas concretizações no princípio da igualdade e na tendência para a generalização. Acontece ainda que outro valor supremo, a segurança jurídica, aponta na mesma direção. Também ela pressiona, em todas as suas manifestações - seja como determinabilidade e previsibilidade do direito, como estabilidade e continuidade da legislação e da jurisprudência ou simplesmente como praticabilidade da aplicação do direito - para a formação de um sistema, pois todos esses postulados podem ser muito melhor prosseguidos através de um direito adequadamente ordenado, dominado por poucos e alcançáveis princípios, portanto um direito ordenado em sistema, do que por uma multiplicidade inabarcável de normas singulares desconexas e em demasiado fácil contradição umas com as outras.

Seguindo com a hipótese de trabalho que toma justiça e segurança por tópoi retóricos do direito, no sentido de lugares da compreensão e argumentação jurídicas, podemos definir uma semântica usualmente atrelada ao emprego dos dois conceitos. Podemos tanto nos restringir ao problema específico da decisão judicial ou à produção do direito como um todo, o que envolveria não só o problema da decisão, mas também o que diz respeito à criação do direito.

É possível entender por produção do direito o processo que é normalmente representado por dois momentos ou operações diferentes: de um lado, a criação; de outro, a aplicação de normas jurídicas. A concepção moderna e já tradicional da produção do direito entende esses dois momentos como etapas distintas que devem ser de competência de órgãos distintos. Seria a distinção das competências para criar e aplicar o direito responsável por garantir a racionalidade das decisões 
judiciais e sua imunização contra o arbítrio e o subjetivismo do julgador. Ou seja, a racionalidade jurídica moderna depende do fato de que o responsável por aplicar uma norma não deve ser contemporaneamente responsável por criar a norma a ser aplicada. No entanto, o que se vê é a proliferação de teorias que demonstram ou defendem exatamente o contrário: que a racionalidade do direito está no reconhecimento de que toda decisão judicial implica criação do direito. Mesmo a autoridade que é apenas competente para aplicar uma norma é necessariamente criadora de direito. As teorias vão desde uma posição mais contida, quando defendem que a autoridade que aplica a norma cria apenas parte da norma dentro do limite de uma moldura (KELSEN, 1987, p. 366), até posições mais extremadas que afirmam não existir norma alguma antes do ato decidir (MÜLLER, 1976, p. 257).

Essa discussão acerca dos limites à criatividade judicial e da vinculação da decisão à norma prévia nos processos decisórios está relacionada aos sentidos que são geralmente atribuídos à justiça e segurança. No senso comum jurídico - que interessa diretamente em nossa investigação tópica -, justiça normalmente é traduzida em termos de mudança ou adequação, isto é, adequação valorativa aos fatos; enquanto segurança significaria estabilidade ou permanência, isto é, manutenção da ordem. Tomando justiça como mudança ou adequação, a estrutura lógica do raciocínio seria necessariamente indutiva e o decisor levaria em consideração mais os elementos específicos do caso do que as diretrizes genéricas da norma. Assim, diante da prevalência do valor da justiça, como cada caso é um caso (mais um tópos relevante para o jurista), o decisor deveria partir das características particulares do caso em tela para chegar a uma decisão justa para aquele caso específico. Já no caso de prevalência do valor da segurança, entendida como manutenção da ordem, a forma mais adequada de raciocínio a ser empregada seria a da inferência dedutiva que procura adequar os fatos e classificar a realidade empírica de acordo com as categorias normativas. Em síntese, justiça e segurança, diante de casos ou problemas concretos, são em geral traduzidas, respectivamente, em termos de mudança e estabilidade. 
Entre as noções de mudança e estabilidade, são fixadas as diferentes variações da fórmula do suum cuique tribuere (dar a cada um o seu) como "a cada um o mesmo", "a cada um segundo seus méritos", "a cada um segundo suas necessidades", "a cada um segundo sua posição", "a cada um segundo suas obras", "a cada um segundo o que a lei lhe atribui” (PERELMAN, 2002, p. 18). Cada variante da fórmula suscita o desenvolvimento de diferentes tópicas. Isto é, cada uma assume um ponto de partida próprio, podendo se aproximar mais ou menos do tópos da igualdade, da equivalência, da proporção, da necessidade, da categoria etc. É assim, pois, que se fala em "justiçaigualdade" de diversas formas, em geral contraditórias entre si, como justiça distributiva, justiça caritativa, justiça comutativa, justiça material, justiça formal, justiça estática, justiça dinâmica e assim por diante. As variações do conceito de justiça dependem da mudança do tópos em que se apoia.

Um exemplo pertinente da dogmática jurídica brasileira que ilustra a oposição entre mudança e estabilidade, isto é, entre justiça e segurança, pode ser obtido com a contraposição entre o texto legal do art. 485, V, do Código de Processo Civil brasileiro, que define a ação rescisória, e a súmula 343 do Supremo Tribunal Federal, que limita o uso do instituto processual. A lei contém o seguinte texto: "Art. 485. A sentença de mérito, transitada em julgado, pode ser rescindida quando: V- violar literal disposição de lei". Enquanto a súmula do tribunal diz: "Súmula 343. Não cabe ação rescisória por ofensa a literal disposição de lei, quando a decisão rescindenda se tiver baseado em texto legal de interpretação controvertida nos tribunais". O texto da lei poderia ser tomado como um exemplo de prevalência do valor da justiça, pois permite que uma questão judicial, já transitada em julgado, possa novamente ser discutida judicialmente. Isto é, mesmo diante da coisa julgada, seria admissível a mudança da decisão em razão da interpretação equivocada de uma disposição legal. Já a súmula limita a possibilidade de mudança, isto é, do recurso à ação rescisória, diante de casos em que o texto legal tenha interpretação controvertida, garantindo assim a prevalência da decisão transitada em julgado e a estabilidade ou manutenção da coisa julgada. 
No entanto, o exemplo poderia muito bem ser invertido, fazendo com que o texto da súmula fosse lido como um caso de prevalência do valor da justiça e o texto do código, como manifestação de prevalência do valor da segurança. Quando o código menciona a violação de "literal disposição de lei", pode-se interpretar que há um sentido literal imanente ao texto legal suscitado na decisão judicial em questão. A violação do sentido literal significa que o sentido imanente ao texto que deveria ser mantido não foi observado. Ou seja, a decisão poderia ser rescindida em razão de não se ter mantido uma situação estável cristalizada no passado, isto é, já contida em potência no texto da lei. A mudança da coisa julgada se deve ao fato de que deveria preponderar a estabilidade do sentido literal, desprezado na sentença judicial. Então, a ação rescisória, nesse caso, não implicaria mudança, mas estabilidade em termos semânticos, devido à manutenção de um sentido literal já existente na lei que foi desprezado ou violado nos termos do código.

No mesmo sentido, o texto da súmula poderia ser lido não mais como atualização do princípio da manutenção da ordem ou como vinculação ao valor da segurança jurídica e prevalência da coisa julgada, mas como um instrumento de justiça diante da controvérsia das interpretações dos tribunais. A súmula defende que diante da "interpretação controvertida dos tribunais" não há um sentido literal do texto legal e o decisor é responsável por interpretar o texto da norma de maneira que seja adequado à situação concreta do caso, pois a controvérsia implica a atual constância da mutabilidade nas interpretações.

Com esse exemplo, pretende-se mostrar como justiça e segurança podem ser traduzidas como mudança e estabilidade, a depender do contexto ou dos interesses ou estratégias em jogo. Ou seja, justiça não é necessariamente mudança, pois pode ser entendida também como estabilidade, no sentido de continuação de uma tradição, igualdade de tratamento ou coerência e linearidade do pensamento. E segurança não é necessariamente estabilidade, pois pode ser do mesmo modo compreendida como aprendizado ou variação intelectiva diante da introdução de novos valores, ou com a possibilidade de diferentes contextos ou mesmo de interpretações divergentes de um mesmo texto. 
Assim, tanto o art. 485, V, do CPC quanto a súmula 343 do STF podem ser paradigmas de justiça ou de segurança, a depender do sentido que seja retoricamente adequado à estratégia que se pretende adotar.

Posição teórica que sustenta essa ambivalência do sentido de justiça é a de Canaris (1996), anteriormente apresentada. Mesmo fazendo parte de uma tradição opositora das teorias tópicas e retóricas do direito, reconhece indiretamente o caráter semântico mutável dos conceitos. Se por um lado o autor apresenta justiça como mudança ou adequação valorativa, isto é, como uma maneira "de tratar o igual de modo igual e o diferente de forma diferente, de acordo com a medida de sua diferença" (CANARIS, 1996, p. 18), por outro lado, logo em seguida, apresenta o conceito de justiça como estabilidade, ou seja, sua concretização "no princípio da igualdade e na tendência para a generalização". Essa "tendência generalizadora da justiça, que exige a superação dos numerosos aspectos possivelmente relevantes no caso concreto, a favor de uns poucos princípios, abstratos e gerais" (CANARIS, 1996, p. 20) é característica típica dos tópoi da permanência e da estabilidade, normalmente atribuídos ao valor da segurança jurídica. O próprio Canaris (1996, p. 22) reconhece que segurança jurídica pressupõe diferentes formas de manifestação, "seja como determinabilidade e previsibilidade do direito, como estabilidade e continuidade da legislação e da jurisprudência ou simplesmente como praticabilidade da aplicação do direito".

A apresentação ambígua dos conceitos de segurança e justiça, à primeira vista, parece levar a uma situação de contradição ou incoerência. Mas isso não acontece se entendermos esses valores não como conceitos unívocos estáveis, mas tópoi que, por sua vez, relacionam-se com outros tópoi, como, de um lado, o da mudança, o da adequação e o da diferença; ou, de outro lado, o da permanência, o da estabilidade e o da igualdade. O que determinará se os tópoi de justiça e segurança assumirão o caráter de mudança ou permanência são as estruturas retóricas presentes nas disputas e nas estratégias de persuasão selecionadas pelos envolvidos na argumentação judicial. Outro ponto de vista teórico pode ser suscitado para corroborar a 
tese. É o caso de considerar a justiça como um "código doador de sentido" ao direito que nos permite estimá-lo como legítimo ou ilegítimo (FERRAZ JR., 1988, p. 321). Nesse sentido, justiça seria uma espécie de "estrutura de resistência à mudança", ou seja, um princípio que se impõe normativamente contra a realidade empírica.

Apesar do caráter de generalidade desses tópoi no direito, a sua construção retórica é sempre uma novidade para cada caso tomado singularmente. O que garante a mútua possibilidade de permanência e mudança, isto é, de manutenção da ordem e adequação à realidade, é a estrutura indutiva do pensamento jurídico.

\section{Criatividade judicial e raciocínio jurídico indutivo}

Entendidos agora na qualidade de tópoi do direito, justiça e segurança são tomados como princípios orientadores do raciocínio jurídico, o que as teorias anglo-fônicas costumam chamar de legal reasoning. Ambos os valores são realizados empiricamente em razão da maneira como a decisão judicial se vincula racionalmente às normas jurídicas previamente estabelecidas em relação aos problemas concretos. Segurança e justiça, ao mesmo tempo em que são princípios orientadores, são também o produto do raciocínio jurídico logicamente determinado. Ou seja, os valores da segurança e justiça são garantidos na medida em que o raciocínio jurídico é logicamente correto.

Tradicionalmente, no mundo ocidental, são apresentadas duas formas lógicas que garantem a racionalidade das decisões e sua vinculação em relação às normas que dependem do sistema jurídico no qual se inserem. Na tradição do direito legislado, o statutory law, também apelidado de sistema romanista ou continental, que representa o núcleo da produção jurídica do assim chamado civil law, prevalece no senso comum teórico dos juristas a ideia de que o raciocínio jurídico é guiado pelas formas lógicas dedutivas. Já na tradição do direito jurisprudencial, o case law, que representa uma parte significativa do sistema do common law, prevalecem as formas analógicas de raciocínio. Pode-se 
dizer que, enquanto no primeiro caso segurança e justiça são produtos da aplicação de uma regra geral por meio de uma inferência dedutiva, no segundo caso, justiça e segurança são garantidas por uma inferência analógica. Em ambos os casos, contudo, existe uma vinculação lógica ou formal entre a decisão judicial e uma norma geral prévia, mesmo que no direito jurisprudencial, diferentemente do que ocorre no direito legislado, essa vinculação não seja imediata.

No direito legislado, a vinculação entre norma geral e decisão judicial seria garantida logicamente por uma relação direta de subsunção do caso à norma, isto é, a decisão judicial seria a conclusão lógica de uma inferência dedutiva dos dados do caso aos preceitos genéricos da norma. É o assim chamado "silogismo de determinação da consequência jurídica” (LARENZ, 1997, p. 381). No direito jurisprudencial, mesmo diante de uma relação analógica entre os casos, isto é, o caso a ser decidido e o caso prévio que forma o precedente judicial, existem princípios genéricos que proporcionam a analogia. Dessa forma, é como se ambos os casos estivessem vinculados a uma norma geral, normalmente compreendida em termos de uma ratio decidendi.

Mas não são apenas essas as duas formas lógicas de raciocínio judicial. Mesmo que as teorias do direito se refiram quase que exclusivamente apenas ao silogismo e à analogia como únicas ferramentas lógico-jurídicas para o direito legislado e o direito jurisprudencial, respectivamente (HUNTER, 1998, p. 367), o caráter tópico-retórico do direito nos leva a pensar na indução como sendo uma ferramenta provavelmente mais adequada para se compreender o processo de inferência que acontece nos tribunais.

Tomando justiça e segurança como parâmetros para a obtenção do direito por meio de procedimentos inferenciais, o decisor se vê obrigado, por um lado, a adequar seu juízo às particularidades do caso a ser resolvido, respeitando a singularidade de cada problema concreto e, por outro, constrangido a limitar as possíveis soluções para o problema a um campo previamente delimitado por uma série de textos jurídicos normativos. Ou seja, o decisor, diante de cada nova situação, sempre 
se encontrará diante dos tópoi da mudança e da estabilidade. Isso quer dizer que, ao mesmo tempo em que cada nova situação representa um evento novo e singular, implicando na adequação do direito à realidade, existe também a previsibilidade de que cada novo fato só encontrará uma resposta no direito desde que se se condicionar à ordem previamente estabelecida.

O raciocínio indutivo leva em consideração tanto os aspectos permanentes na multiplicidade de casos como as particularidades de cada novo caso. É assim que é possível generalizar princípios e teorias a partir de um conjunto de precedentes ou examinar uma série de decisões judiciais de um determinado tribunal e concluir que uma única rubrica encobre todos os casos, ou mesmo prever que a abordagem de um determinado assunto feita pelo tribunal está mudando em alguma direção (HUNTER, 1998, p. 365). Mas, como dito, apesar de o raciocínio indutivo ser fundamental para o raciocínio humano, está praticamente ausente nas discussões sobre o raciocínio jurídico, enquanto a dedução parece ser entendida como o meio mais óbvio de produção normativa no âmbito do direito legislado, e a analogia no âmbito do direito jurisprudencial. E não são apenas as teorias lógicas ou racionalistas do direito (MACCORMICK, 1997, p. 19) que propagam essa ideia, até as teorias retóricas terminam por amplificar o papel da dedução do direito, mesmo que sob outras formas, como a do entimema (SOBOTA, 1995). Ou seja, mesmo os retóricos que, em tese, são opositores das teorias silogísticas ou subsuntivas do direito, com sua crítica à pertinência dos métodos dedutivos no raciocínio judicial, contribuem para a proliferação de teses dedutivistas no direito, ainda que com outra roupagem teórica. Já na tradição do common law, muito se fala em analogia, como o case law method (HUNTER, 1998, p. 367), isto é, o método adequado à comparação entre um caso passado (precedente) e um atual, destinado ao descobrimento (ou produção, a depender do ponto de vista) de similaridades relevantes. No que se refere à indução, há pouca referência nos trabalhos dos juristas. O que se pretende examinar aqui é qual o grau de relevância da indução para o raciocínio jurídico, assumido o caráter tópico-retórico do direito. 
Algumas razões podem ser relevantes para se considerar a indução uma ferramenta importante para compreender o raciocínio jurídico (HUNTER, 1998, p. 368). Em primeiro lugar, sabemos que os advogados são capazes de afirmar com relativa segurança, a partir da experiência, qual será a opinião de um juiz sobre determinada matéria. Por exemplo, é possível dizer se um caso terá ou não sucesso em razão da evolução num sentido ou noutro da doutrina jurídica. Da mesma forma, é possível catalogar as decisões judiciais e uma multiplicidade de precedentes em um framework relativamente coerente de regras e princípios. Em segundo lugar, no direito jurisprudencial, âmbito no qual a analogia é talvez mais relevante para o sistema judicial, é possível identificar inúmeros pontos de contato entre o raciocínio analógico e o indutivo que tornam as operações lógicas relativamente indistinguíveis. Tanto a analogia quanto a indução se baseiam na experiência prévia, enquanto, muitas vezes, é a indução a base para o raciocínio analógico de comparação entre o passado e o presente. Em terceiro lugar, a indução é o instrumento metodológico por excelência das teorias críticas e sociológicas do direito. Tanto a teoria crítica quanto os sociólogos do direito estão muito mais preocupados em saber o que o direito é de fato na experiência do que saber o que os doutrinadores dizem o que o direito é. A análise sociológica dos dados que são obtidos a partir dos casos é o que permite o trabalho de generalização de informações sobre um domínio determinado. Em quarto lugar, a indução é, sem dúvida, uma forma de raciocínio jurídico importante para a construção de modelos de decisão. Isso não apenas para o direito comum ou jurisprudencial, mas também, a despeito do senso comum, no direito legislado. Entender o processo judicial requer entender como funciona a indução, isto é, o pensar a partir de casos.

O raciocínio jurídico indutivo pode ser desmembrado em um processo de dois estágios (HUNTER, 1998, p. 369). Em primeiro lugar, é realizada uma generalização indutiva derivada, ou uma generalização da regra a partir de dados observacionais, o que se chama de aprendizado indutivo. Essa primeira etapa consiste em selecionar um número de casos ou instâncias, isto é, de experiências isoladas, de acordo com 
seus atributos e consequências relevantes para posteriormente derivar desses atributos e consequências uma ampla regra aplicável, ou seja, uma regra geral que cubra todas as instâncias examinadas. Em segundo lugar, aplica-se a regra indutivamente derivada por meio de uma inferência dedutiva. Se essa aplicação da regra geral é silogística ou entimemática é um ponto que não cabe discutir aqui, mas não deixa de ser relevante para a compreensão da aplicação da lógica no direito (PARINI, 2009, p. 153). Em síntese, o raciocínio indutivo é composto por um aprendizado indutivo e uma inferência dedutiva.

Em geral, a indução é considerada uma forma lógica excepcional do raciocínio judicial (FERRAZ JR., 1988, p. 275), especialmente no direito legislado, em cujo âmbito prevalecem as teses e os métodos dedutivistas. A tradição do pensamento positivista no direito, de fato, tende a privilegiar o as conclusões dedutivas, em razão do rigor lógico de sua demonstração no plano teorético, enquanto a conclusão indutiva, isto é, do particular para o geral, tende a ser considerada "como logicamente mais problemática do que a conclusão dedutiva" (ENGISCH, 1996, p. 289). De acordo com essa tradição, a indução só seria admitida quando a dedução não fosse possível, ou seja, nos famosos casos de lacunas normativas, a indução funcionaria apenas como instrumento de integração no direito.

Há pelo menos duas formas genéricas de classificação da indução. A primeira diferencia a indução sumariante da indução ampliativa (HUNTER, 1998, p. 370). Ela não representa um instrumento útil ao jurista, pois corresponde à simples generalização de uma situação em que todas as instâncias possíveis são conhecidas, sendo incapaz de fazer previsões futuras. Já a indução ampliativa ou amplificadora, normalmente concebida restritivamente como método de integração do direito, é capaz de produzir generalizações e fazer previsões que vão além dos dados presentes ou atuais. Com a indução ampliativa, é possível, por exemplo, prever como os juízes decidirão determinada matéria no futuro. As profecias que antecipam o comportamento futuro das cortes são, de certa forma, obtidas indutivamente a partir das 
generalizações sobre uma cadeia de comportamentos que apresenta certas regularidades.

Uma segunda diferenciação se fundamenta na quantidade e na variedade de casos examinados (HUNTER, 1998, p. 371). Quando se privilegia a quantidade em detrimento da variedade, chama-se indução enumerativa. Esse tipo de indução depende da quantidade de casos semelhantes ou da quantidade de dados observáveis. Por exemplo, os seres humanos são mortais. A grande quantidade de dados observados garante a certeza da generalização obtida indutivamente. Diferentemente, quando se privilegia a variedade de casos, fala-se em indução variativa. Aqui, a indução depende da variedade dos dados observados e de suas diferentes instâncias para produzir uma generalização segura. Poderíamos observar, por exemplo, que não apenas os seres humanos são mortais, mas que a mortalidade é uma característica presente em todos os seres vivos, independentemente da espécie, se animal ou vegetal, forte ou frágil, dotada ou não de longevidade.

Se, por um lado, podemos afirmar que a relevância da indução ampliativa para o jurista é infinitamente maior em relação à indução sumariante, o mesmo não se pode dizer em relação à indução enumerativa e à indução variativa. Não há como determinar se é preferível uma grande quantidade de casos ou a sua variedade como forma de obter certeza com relação à regra geral indutivamente obtida. Isso não apenas no direito, mas na ciência de uma maneira geral. A indução enumerativa pode ser considerada ingênua, pois é a variedade de testes que garante que hipóteses falsas sejam excluídas. Mas o contrário também pode ser afirmado, já que a indução enumerativa é mais confiável diante da grande quantidade de casos observados, pois a inferência indutiva nunca pode ser provada como absolutamente verdadeira. Portanto, quanto maior a multiplicidade das instâncias, maior será a crença na indução. O que se pode afirmar é que ambas as formas de indução, a enumerativa e a variativa, são operacionalmente relevantes para o raciocínio jurídico, pois nem sempre o jurista é capaz de contar com uma grande quantidade de casos relacionados a uma só 
matéria, devendo recorrer a uma variedade de casos que compartilhem traços característicos relevantes.

Uma teoria retórica do direito é obrigada a reconhecer o papel fundamental que os exemplos ou paradigmas desempenham na argumentação judicial. $\mathrm{E}$ isso vale tanto para o sistema jurídico baseado na lei quanto para o sistema baseado no precedente. Os casos passados e suas soluções servem como referenciais para possíveis casos futuros. Ainda que não exista uma vinculação formal entre a decisão passada e o caso atual, como na tradição do direito legislado, retoricamente, o exemplo passado exerce influência significativa nos rumos que serão tomados para decidir os casos futuros. Mesmo Aristóteles, que privilegia os argumentos dedutivos (o silogismo na dialética e o entimema na retórica), reconhece a força persuasiva dos discursos fundados em exemplos (ARISTÓTELES, 1996, p. 17 [1356b]). O que dizer, então, a respeito do poder de influência no raciocínio proporcionado por uma cadeia de exemplos capazes de levar a uma generalização de expectativa, como ocorre na indução? Em qualquer forma de raciocínio indutivo, sumariante ou ampliativo, enumerativo ou variativo, o que há não é apenas uma comparação entre um caso e outro, mas uma comparação global entre uma multiplicidade de casos que levam a uma formulação geral que incute no próprio observador e no seu auditório o valor da coerência e o da continuidade na cadeia de dados observados.

Normalmente, o que as teorias positivistas - mas não só as positivistas - tradicionais do raciocínio jurídico defendem é que a racionalidade do direito se perfaz com a correção lógica dos juízos e que o modelo de raciocínio por excelência é o dedutivo, isto é, o da subsunção do fato à norma jurídica geral prévia. O que não é explicitado por essas teorias é que a norma geral prévia dificilmente é obtida dedutivamente, pois mesmo uma norma legal promulgada em um código depende da experiência prática e do trabalho contínuo de decidir dos tribunais. Por mais que a norma válida se desvincule de sua origem fática, isto é, de sua dependência direta em relação à experiência, a sua formação é sempre dependente de uma tradição, mesmo que de uma 
contratradição ou do desejo de se contrapor a uma tradição já não mais condizente com os atuais valores e as novas expectativas.

O que se pensa, então, é que no direito legislado se deve aplicar a dedução e apenas no direito jurisprudencial é que têm pertinência a analogia e a indução. Entretanto, o processo de aplicação do direito não pode ser considerado como um processo de aplicação de normas já previamente conhecidas a fatos diversos. As normas são descobertas (ou construídas) por meio do processo de identificação de semelhanças e diferenças entre os casos. É o chamado processo de classificação e criação normativa, uma espécie de processo dinâmico de classificação e reclassificação que ocorre à medida que cada novo caso é decidido (HUNTER, 1998, p. 374). À medida que os casos são construídos e comparados entre si, os conceitos jurídicos começam a ser elaborados. Em seguida, o conceito passa a ser relativamente fixado (mesmo que novos exemplos ainda possam ser classificados como dentro ou fora do conceito). Até que se chega ao colapso do conceito: quando o conceito não tem mais aplicação aos novos exemplos e deixa de ter influência no raciocínio jurídico.

No raciocínio jurídico, a classificação se modifica conforme a própria classificação é feita. Isso significaria dizer que as regras mudam no momento mesmo em que são aplicadas, ou que a comparação de novos fatos a normas prévias leva à criação de normas atuais ou atualizadas. A norma não permanece incólume aos fatos: à medida que uma norma é aplicada a diversos fatos, o seu significado se modifica, indutivamente, por uma conversão semântica. É o que se consolida em um contínuo processo de inferência indutiva.

Mas isso não quer dizer que as normas se modifiquem ou sofram alterações semânticas de modo arbitrário e completamente imprevisível. Existe estabilidade no processo de produção das decisões, mesmo em períodos de grandes mudanças (HUNTER, 1998, p. 375). Normas indutivamente geradas são garantidas tanto por indução enumerativa quanto por indução variativa. O próprio processo de indução pode sofrer variações a partir da inserção de novos dados. O direito muda e as 
suas regras indutivas também mudam. Mas a mudança de inferências geradas indutivamente é uma parte normal do processo de inferência indutiva. Nesse caso, a inferência indutiva pode ser usada de duas maneiras: para entender o estado atual do direito ou para decidir um caso particular. Princípios indutivamente derivados não permanecem constantes ou imutáveis, pois a inferência indutiva é contínua e dinâmica, devendo dar conta das numerosas mudanças, mesmo as mais sutis. A conclusão a que podemos chegar é que as normas não são a-históricas ou atemporais.

Mas por que há um esforço das teorias dogmáticas em demonstrar exatamente o contrário: que são as normas que modificam e interferem no sentido dos fatos em vez de serem as normas gerais prévias a determinarem o que é juridicamente relevante? Por que a indução é rechaçada e considerada apenas um modo excepcional de produção do direito, utilizável apenas quando a dedução ou a analogia não podem atuar? Talvez seja em razão do fato de que sempre há uma relativa obscuridade na indução.

A indução é vulnerável, especialmente a enumerativa. O processo inferencial da indução simplesmente pode tomar um rumo completamente diverso do original, em razão da inserção de novos dados ou simplesmente em razão de uma nova interpretação dos dados anteriormente observados ou da detecção de novas características salientes. Mesmo que os juristas recorram à indução para derivar generalizações sobre o direito, os fatores utilizados na inferência serão variáveis. Além disso, a explicação oferecida pela simples indução não é satisfatória para justificar a decisão de um caso. Toda explicação requer hipóteses (teorias ou princípios) como forma de justificar a decisão. Dessa forma, somos obrigados a fornecer razões ou justificativas. 0 raciocínio indutivo por si só é fracamente garantido, pois se baseia apenas na regularidade da experiência como pano de fundo para a criação da regra.

A regularidade da experiência é uma garantia pobre para qualquer decisão judicial. É preciso abstrair um princípio mais geral que controle 
a solução dos casos e que justifique racionalmente as decisões. Mas, nesse sentido, até que ponto justificação é algo diferente de crença? A justificação lógica depende de uma ideia de causalidade, isto é, de que algo é ou existe em razão de uma determinada causa. Mas essa relação entre causa e efeito pode muito bem ser concebida como a mera constatação de uma regularidade, de um fenômeno que acontece com frequência, mas que não passa de uma retórica ou de um logos que conecta ideias distintas de diferentes objetos, ou de mero hábito (HUME, 2003, p. 77).

Se não é a regularidade justificação, apenas o princípio explanatório de uma ou mais regras gerais será capaz de garantir confiança. A inferência indutiva por si só não garante confiança na generalização derivada do processo indutivo. Para obter um princípio explanatório, é preciso relacionar mais dois tipos de inferência: somadas à indução, a abdução e a retrodução permitem ir além da mera observação dos fatos e até da generalização indutiva, chegando a formular um princípio explanatório que justifica as regularidades observadas e as previsões conjecturadas. Partindo-se da diferenciação estabelecida por Charles S. Peirce entre indução quantitativa e indução qualitativa, isto é, respectivamente, a indução que proporciona generalização predicativa, mas não fornece hipóteses subjacentes e a indução que, além de generalizar regularidades apresenta as hipóteses teóricas que as fundamentam, é possível dizer que as teorias jurídicas mais próximas da realidade do direito são aquelas que se fundamentam em processos indutivos qualitativos de observação.

No processo de indução qualitativa, há duas fases: em primeiro lugar, o procedimento de observação e, em segundo lugar, a projeção de um conjunto de hipóteses. O trabalho do teórico ou observador do direito não se completa senão com um novo procedimento inferencial de abdução, isto é, um processo de proliferação das hipóteses. Mas na abdução, esse processo tende ao infinito diante do número infinito de potenciais hipóteses de justificação ou princípios explanatórios.

Para separar as boas das más hipóteses, seria preciso aplicar cada uma para prever a solução de novos casos. O que impede que o 
trabalho do teórico o leve a formulações de aporias é o procedimento lógico da retrodução, ou seja, o processo de eliminação de hipóteses obtidas abdutivamente. Mas a tendência ao infinito do trabalho lógico de investigação dos princípios explanatórios não termina com a retrodução simplesmente.

Assim, a indução, somada à abdução e à retrodução, opera em conjunto para gerar um sistema autocorretivo de hipóteses explanatórias e justificatórias. Mas como encontrar hipóteses plausíveis dentro de um conjunto infinito de hipóteses? O que acontece se a hipótese se modifica com o tempo? Como se tem a acesso à correção da hipótese? $\mathrm{O}$ procedimento de determinação da hipótese correta não pode se restringir ao processo retrodutivo de eliminação das hipóteses equivocadas. Isso seria da mesma forma um trabalho infinito, em razão do número potencialmente infinito de hipóteses abdutivamente geradas. Peirce, talvez se inspirando no otimismo ético-gnoseológico de Aristóteles (1996, p. 9), que diz que "os homens tem uma suficiente disposição natural para o verdadeiro e na maior parte dos casos colhem a verdade", entende os seres humanos como sendo geneticamente predispostos para encontrar as hipóteses corretas, ou têm um instinto animal para encontrar a verdade.

Mas a solução para o problema de se cair sempre em aporias é realmente essa? A mente humana de fato é predisposta a encontrar as hipóteses corretas? Há um instinto animal de separar as hipóteses mais plausíveis das mais implausíveis? Seria esse o fundamento para se adotar um método heurístico de investigação? É isso que se chama de método de tentativa e erro? Parece que não se pode separar completamente o âmbito da justificação racional do âmbito da pura crença. Em alguma medida, as crenças são racionalmente fundamentadas; e, da mesma forma, as justificações racionais são, em alguma medida, fruto da crença.

De qualquer forma, admitindo com certo grau de otimismo que existe um instinto para a verdade nos seres humanos, podemos afirmar que os juristas devem ter um instinto indutivo que Ihes permite interpretar mudanças na atividade judicial e assim produzir novos 
princípios, regras ou predições. E se não for realmente um instinto, é ao menos uma habilidade importante na experiência jurídica não só teórica como prática. O raciocínio generalizante do jurista é proporcionado pela inferência indutiva, abdutiva e retrodutiva. O estudante de direito deve ser treinado a abduzir hipóteses de maneira eficaz.

\section{Conclusão}

Qualquer hipótese explanatória no direito é uma garantia apenas contingente. Em virtude do eterno duelo entre normatividade e faticidade no direito, ou entre validade e eficácia das normas jurídicas, o que temos é um conjunto de regras técnicas da dogmática jurídica que se adaptam a novos dados empíricos ou novas formas de observação e interpretação da realidade fenomênica. As hipóteses explanatórias do direito são selecionadas segundo códigos que controlam as inferências dedutivas ao passo em que são indutivamente gerados, formando assim uma série de regularidades, ou estruturas dinâmicas e mutáveis.

A vinculação formal entre normas e fatos é uma garantia persuasiva usada para justificar uma solução preferida. Esse é um aspecto crítico da própria racionalidade jurídica. Não há como separar, no direito, epistemologia de ideologia, ou deixar de reduzir conhecimento a opinião na retórica prática da dogmática jurídica. A noção de garantia justifica a aceitação social da decisão. O que teoricamente é tomado por certo serve de garantia de racionalidade e, portanto, de ausência de arbitrariedade em relação às decisões.

A retórica atua como alicerce que nos permite entender como a explicação do direito é abdutivamente gerada. Ou seja, é a finalidade de persuadir e convencer que determina as escolhas estratégicas dos princípios explanatórios do direito, o que nos leva a concluir que o princípio explanatório é persuasivo no direito. Diferentemente - mas não tanto - da atitude científica, as generalizações e os postulados teóricos que as fundamentam servem estrategicamente como retórica prática da dogmática jurídica, destinada principalmente a doutrinar e 
neutralizar perspectivas teoréticas antagônicas ou mesmo ambíguas. Todo processo de decisão, portanto, é um processo de criação do direito. Essa não é uma conclusão mais do que óbvia, mesmo (ou até principalmente, eu diria) para as teorias positivistas do direito. Como dito por Kelsen, não há método científico algum que garanta a escolha de uma interpretação ou outra dos textos normativos. A decisão é sempre, em alguma medida, um ato de vontade e depende, portanto, pelo menos minimamente, da inventividade e subjetividade de cada decisor. Cada nova decisão é reintroduzida no conjunto de dados observáveis e gera uma nova situação que deverá ser novamente inferida/interpretada. $\mathrm{O}$ mundo das normas não é distinto da realidade empírica. Ao contrário, é a realidade levada em consideração pelo jurista que determina o sentido de uma norma.

Como visto, segurança e justiça são princípios muito amplos que podem ser traduzidos de diversas maneiras, entre uma tópica da mudança e uma tópica da estabilidade. Nem a justiça é apenas garantida pela adequação do direito às peculiaridades de um caso, por meio de um procedimento inferencial indutivo que parte da realidade; tampouco é a segurança garantida por um processo dedutivo de adequação da realidade às normas. Ambos os valores, justiça e segurança, dependem das regularidades que são indutivamente determinadas ou estabelecidas e dos princípios explanatórios que as fundamentam. Se estabilidade pressupõe mudança e mudança pressupõe estabilidade, justiça e segurança são partes de uma só coisa. Justiça e segurança, antes de se excluírem mutuamente, são tópoi complementares e interdependentes.

\section{Referências}

ARISTÓTELES. Retórica. Tradução de M. Dorati. Milano: Mondadori, 1996.

BALLWEG, Ottmar. Analytical rhetoric, semiotic and law. In: KEVELSON, Roberta. Law and Semiotics. New York: Plenum Press, 1987. v.1. p. 25-33. 
Analytische Rhetorik als juristische Grundlagenforschung. In: ALEXY, R.; DREIER, R.; NEUMANN, U. (Hrsg.). Archiv für rechts-und sozialphilosophie. Beiheft 44. Stuttgart: Franz Steiner Verlag, 1991a. p. 45-54.

. Phronetik, semiotik und rhetorik. In: BALLWEG, Ottmar; SEIBERT, Thomas-Michael (Hrsg.). Rhetorische rechtstheorie. Freiburg/München: Verlag Karl Alber, 1982.

- Retórica analítica e direito. Tradução de João Maurício Adeodato. Revista Brasileira de Filosofia, São Paulo, v. 34, n. 163, p. 175-184, jul./ago./set. 1991b.

BITZER, Lloyd. The rhetorical situation. Philosophy \& rhetoric, Pennsylvania, v. 1, n. 1, p. 1-14, winter, 1968.

BRINTON, Alan. Situation in the theory of rhetoric. Philosophy \& Rhetoric, Pennsylvania State University Press, v. 14, n. 4, p. 234-248, fall, 1981.

CANARIS, Claus-Wilhelm. Pensamento sistemático e conceito de sistema na ciência do direito. Tradução de A. Menezes Cordeiro. Lisboa: Calouste Gulbenkian, 1996.

ENGISCH, Karl. Introdução ao pensamento jurídico. Tradução de J. B. Machado. Lisboa: Calouste Gulbenkian, 1996.

GIANFORMAGGIO BASTIDA, Letizia. Gli argomenti di Perelman: dalla neutralità dello scienziato all'imparzialità del giudice. Milano: Edizioni di Comunità, 1973.

HUME, David. A treatise of human nature. Mineola: Dover, 2003.

HUNTER, Dan. No wilderness of single instances: inductive inference in law. Journal of Legal Education, Seattle, v. 48, n. 3, p. 365-401, sep. 1998.

KELSEN, Hans. Teoria geral do Direito e do Estado. Tradução de L. C. Borges. São Paulo: Martins Fontes, 1998. 
. Teoria pura do Direito. Tradução de J. B. Machado. São Paulo: Martins Fontes, 1987.

LARENZ, Karl. Metodologia da ciência do Direito. Tradução de J. Lamego. Lisboa: Calouste Gulbenkian, 1997.

LARSON, Richard. Lloyd bitzer's "rhetorical situation" and the classification of discourse. Problems and implications. Philosophy \& Rhetoric, Pennsylvania, v. 3, n. 3, p. 165-168, summer, 1970.

LOSANO, Mario G. Os grandes sistemas jurídicos. Tradução de M. Varejão. São Paulo: Martins Fontes, 2007.

- Verso il bene comune: un sentiero per utopia? Dalla filosofia attraverso la legislazione sino alla vita degna. Rivista internazionale di filosofia del diritto, Milano, serie V, n. 2, p. 193-230, apr./giugno 2003.

MACCORMICK, Neil. Legal reasoning and legal theory. Oxford: Clarendon Press, 1997.

MÜLLER, Friedrich. Einige leitsätze zur juristischen methodik. In: DREIER, Ralf (Hrsg.). Probleme der Verfassungsinterpretation. Baden-Baden: Nomos Verlaggesellschaft, 1976. p. 248-265.

PARINI, Pedro. Retórica, raciocínio dedutivo e as possíveis estruturas lógicas da argumentação jurídica. In: FEITOSA, E.; MAIA, F. J.; FREITAS, L.; BARBOSA, A. O direito como atividade judicial. Recife: Bagaço, 2009. p.149-193.

PERELMAN, Chaïm. Ética e direito. Tradução de J. C. S. Duarte. Lisboa: Instituto Piaget, 2002.

SOBOTA, Katharina. Não Mencione a Norma! Tradução de João Maurício Adeodato. Anuário dos Cursos de Pós-Graduação em Direito, Recife: Universitária, 1995 . n. 7, p. 251-273.

Recebido em: 07/10/2014

Aprovado em: 20/10/2014 